\title{
Growth Factors and Points of the Industrial Policy of the Astrakhan Region (Russia)
}

\author{
Svetlana Arutyunyan*, Elena Gadzhieva, Gennady Berezhnov
}

\author{
Chair of Management, Astrakhan State University, Astrakhan, 414056, Russia \\ *Corresponding author. Email: arutunyan1109@mail.ru
}

\begin{abstract}
The article describes the analysis of the peculiarities of the industry and industrial policy of the Astrakhan Region (Russia) with the application of production function tools. The authors conclude that in the current conditions of Russia in general and the Astrakhan Region in particular it is the most fruitful to develop and implement the mutually beneficial integrated industrial policy in cooperation with the other Caspian Sea states that will further the development of the economic potential and security of the Caspian Sea territory as a whole. The industrial cooperation strategy should be worked out with regard to the model of long-term industrial policy of the region that can be formed and proven using production function tools. The article analyzes the results of the industrial activity in the Astrakhan Region over the past decade, identifies the main trends, problems, factors and development prospects. The authors study the regularities and development trends of the industry branches of the Astrakhan Region using the Cobb-Douglas production function, draw conclusions about the economic efficiency dynamics of some branches of industrial production: the calculation of the production function parameters shows that the efficiency of the industry in the Astrakhan Region is not high, there is the deintensification of production and economic growth.The authors classify and characterize the economic growth factors: extensive, intensive, and market-oriented. They also make a distinction between such concepts as "production intensification" and "economic efficiency", consider the problems that impede the industry development, which results in the decrease of the economic efficiency of production, and determine the reference points for the growth of industrial production.
\end{abstract}

Keywords: industry, industrial policy, economic potential, Cobb-Douglas production function, economic growth factors, production intensification, extensive factors, intensive factors

\section{INTRODUCTION}

Describing the current cooperation of the Caspian Sea littoral states, it is necessary to take into account the following main facts.

Nowadays, the Caspian littoral states compete with each other in the field of oil and gas production and oil refining, gas condensate, oil and gas transportation to other states both by land and by sea, respectively, and the development of oil and gas, shipbuilding, and transport clusters in their territories. At the same time, the attention should be focused on the fact that the importance of the Caspian Sea region as one of the largest sources of hydrocarbon raw materials is rapidly growing with a view to the increase in the world energy consumption.

Azerbaijan, Kazakhstan and Turkmenistan have made considerable efforts to ensure their competitiveness in certain areas, including the above mentioned sphere of economic activity. In particular, it is no secret that the main reserves of Caspian Sea oil are located in the territory of Kazakhstan that is the leader in its production nowadays. Moreover, the transportation of produced raw materials is mainly oriented to the Baku-Tbilisi-Ceyhan pipeline, i.e. bypassing the territory of the Russian Federation.

Additionally, there is an increase in the activity of the shipbuilding enterprises of Iran, Azerbaijan, and Kazakhstan with the growth of production potential which may result in losing of lead by Astrakhan shipbuilding industry, that is cluster-forming for the region's economy, and Astrakhan may be driven from the offshore shipbuilding market [1].

It should also be emphasised that the Baku-Tbilisi-Kars railway, launched in early 2018, raised the appeal of rail transportation through Kazakhstan and Turkmenistan to China, which may cause a risk of reducing the transit of goods through Russia from China to Europe [2].

In this context, the development and implementation of a mutually beneficial integrated industrial policy, that contributes to the development of the economic potential and security of the Caspian Sea area, rather than the competition with the Caspian Sea states is advantageous for Russia as a whole and the Astrakhan Region in particular. To accomplish this, it is necessary to study the conditions and obstacles for such integration and develop an industrial cooperation strategy. 


\section{ANALYSIS AND RESULTS}

The production function, enabling to obtain the generalized quantitative characteristics of the economic system, which can be used to analyze, evaluate and predict the development trends and changes in the production process, is defined by L.L. Terekhov as an economic and mathematical expression of the dependence of production activity results on the indicators-factors that determined these results [3].

This tool can make possible to determine and quantify the relation between the result of production (output, gross domestic product, profit, etc.) and the technical, natural, social, and economic factors that provide this result. In modern research, the development of neoclassical economic theory, as noted by G.B.Kleiner [4], contributed to the use of production functions for arbitrary economic systems of micro-, meso-, macro- and mega-economic levels. Besides, one of the important uses of production functions is to apply them for identifying and evaluating the quantitative and qualitative components of economic growth, determining the contribution of growth factor groups to the production dynamics of the economic system.

The study of patterns and development trends in the industries of the Astrakhan Region with the application of production function tools showed the following.

To characterise the industry of the Astrakhan Region, it should be pointed out, first of all, that it is the leading branch of the regional economy. The volume of industrial production in different years makes $65-70 \%$ of the total gross regional product; therefore, the industry largely determines the efficiency of resource use (natural, material, labour) and production and scientific technical potential of the region.

Table 1 shows the dynamic of the indicators of the Astrakhan Region industry for the past decade (20092018).

Over the past decade, the industrial output of the region has grown 7 times. Comparably to this, the price of fixed assets of the industries increased by 5.8 times (Figure 1).

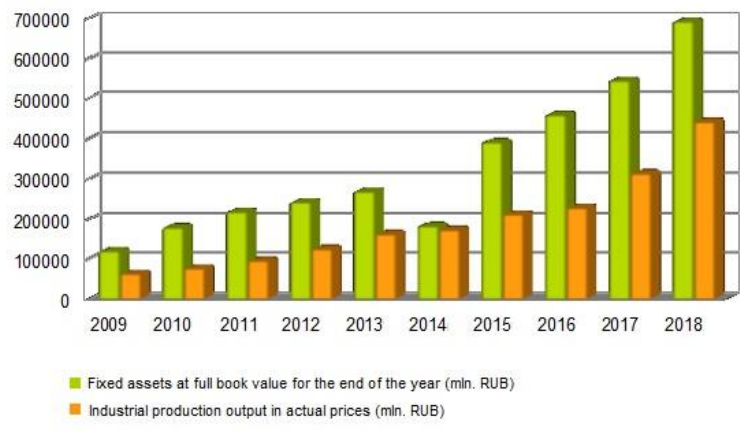

Figure 1 Dynamics of the industrial production output and fixed assets of industry (mln. RUB)
Against the growth in the gross output and price of fixed assets, the number of people employed in industries has decreased by $25 \%$ in 2009-2018 (Figure 2).

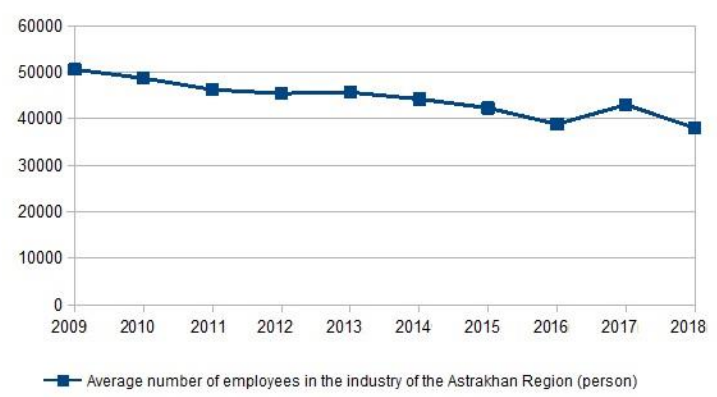

Figure 2 Dynamics in the number of employees in the Astrakhan Region industry (person) [6]

In this case, it is worth noting that the industrial production of the region employs slightly less than $20 \%$ of the total number of employees in the Astrakhan Region economy. The structure of the industrial production underwent a major change during the period of 2009-2018 (Figures 3, 4).

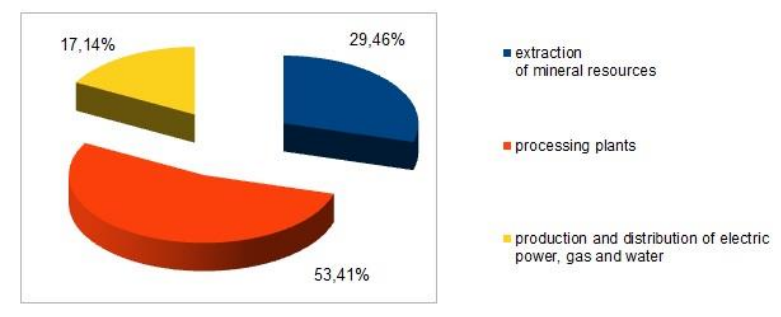

Figure 3 Ratio of the industry branches to the total industrial output in 2009 (\%)
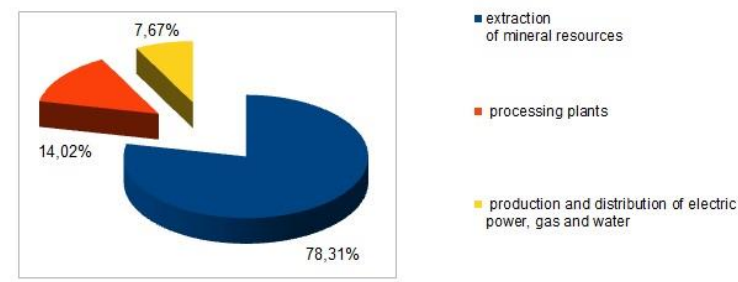

Figure 4 Ratio of the industry branches to the total industrial output in 2018 (\%)

Even 10 years ago, the processing plants accounted for slightly more than $50 \%$ of the total industrial output. Currently, the extraction of mineral resources makes $78.3 \%$ of the production output of the Astrakhan Region. There are also changes in the structure of employment in the industry branches but less considerable (Figures 5, 6). The largest number of employees is recorded in processing plants, the smallest - in the extractive industries. However, the study shows that the number of employees in the industry "extraction of mineral resources" increased from 
intensive. The nature of the applied technologies can be assessed using some parameters of the production function.

The Cobb-Douglas production functions for the regional industries of 2005-2014 were made by the authors in their earlier studies. The production functions for the industries of the Astrakhan Region are presented in Table 2.

The similar structure of the employment is determined by the nature of technologies used in various branches of industrial production - labour-intensive and capital-

Table 1 Indicators of industrial production in the Astrakhan Region (Federal State Statistic Service, 2019) [5]

\begin{tabular}{|c|c|c|c|c|c|c|c|c|c|c|}
\hline Indicators & 2009 & 2010 & 2011 & 2012 & 2013 & 2014 & 2015 & 2016 & 2017 & 2018 \\
\hline $\begin{array}{l}\text { Industrial } \\
\text { production output } \\
\text { in actual prices } \\
\text { (mln. RUB), } \\
\text { including: }\end{array}$ & 62,969 & 76,689 & 95,724 & 125,356 & 162,313 & 173,012 & 211,627 & 227,799 & 313,284 & 441,883 \\
\hline $\begin{array}{l}\text { - extraction of } \\
\text { mineral resources }\end{array}$ & 18,548 & 22,508 & 32,246 & 68,393 & 93,638 & 100,786 & 125,060 & 137,266 & 226,961 & 346,022 \\
\hline - processing plants & 33,631 & 40,938 & 47,863 & 39,812 & 48,551 & 48,602 & 61,014 & 61,189 & 53,839 & 61,946 \\
\hline $\begin{array}{l}\text { - production and } \\
\text { distribution of } \\
\text { electric power, gas } \\
\text { and water }\end{array}$ & 10,790 & 13,238 & 15,615 & 17,150 & 20,124 & 23,624 & 25,553 & 29,710 & 32,484 & 33,915 \\
\hline $\begin{array}{l}\text { Fixed assets at full } \\
\text { book value for the } \\
\text { end of the year } \\
\text { (mln. RUB), } \\
\text { including }\end{array}$ & 119,945 & 178,530 & 217,954 & 241,877 & 268,273 & 182,235 & 390,807 & 458,634 & 544,471 & 691,673 \\
\hline $\begin{array}{l}\text { - extraction of } \\
\text { mineral resources }\end{array}$ & 68,930 & 117,929 & 143,260 & 158,722 & 169,791 & 116,364 & 287,054 & 347,246 & 431,144 & 562,411 \\
\hline - processing plants & 21,333 & 24,497 & 26,232 & 29,701 & 30,161 & 13,006 & 30,791 & 35,732 & 32,824 & 42,041 \\
\hline $\begin{array}{l}\text { - production and } \\
\text { distribution of } \\
\text { electric power, gas } \\
\text { and water }\end{array}$ & 29,682 & 36,104 & 48,462 & 53,454 & 68,321 & 52,865 & 72,962 & 75,656 & 80,503 & 87,221 \\
\hline $\begin{array}{l}\text { Average number of } \\
\text { employees (person), } \\
\text { including: }\end{array}$ & 50,581 & 48,681 & 46,221 & 45,410 & 45,635 & 44,211 & 42,300 & 38,800 & 42,994 & 38,000 \\
\hline $\begin{array}{l}\text { - extraction of } \\
\text { mineral resources }\end{array}$ & 4,889 & 5,007 & 5,071 & 4,946 & 4,941 & 5,133 & 5,000 & 5,000 & 13,243 & 5,300 \\
\hline - processing plants & 32,117 & 30,115 & 28,261 & 27,643 & 27,941 & 26,421 & 25,300 & 22,500 & 15,464 & 19,100 \\
\hline $\begin{array}{l}\text { - production and } \\
\text { distribution of } \\
\text { electric power, gas } \\
\text { and water }\end{array}$ & 13,575 & 13,559 & 12,885 & 12,820 & 12,752 & 12,657 & 12,000 & 11,300 & 14,287 & 13,600 \\
\hline
\end{tabular}


Table 2 Production functions for the industries of the Astrakhan Region *coefficient standard errors are given in brackets

\begin{tabular}{|l|c|c|c|c|c|c|}
\hline \multicolumn{1}{|c|}{ Industry branch } & $\boldsymbol{\alpha}^{*}$ & $\boldsymbol{\beta}^{*}$ & $\boldsymbol{e}^{\boldsymbol{a \mathbf { 0 } ^ { * }}}$ & $\boldsymbol{R}^{\mathbf{2}}$ & $\boldsymbol{F}$ & Production function \\
\hline \multicolumn{1}{|c|}{1} & 3 & 4 & 5 & 6 & 7 & 8 \\
\hline $\begin{array}{l}\text { Entire industry } \\
\text { including }\end{array}$ & $\begin{array}{c}0.474^{*} \\
(0.346)\end{array}$ & $\begin{array}{c}-1.469 \\
(0.997)\end{array}$ & $\begin{array}{c}\mathrm{e}^{21.65} \\
(14.516)\end{array}$ & 0.808117 & $14.74031^{*}$ & $Y=e^{21.65} \cdot K_{t}^{0.474} \cdot L_{t}^{-1.469}$ \\
\hline $\begin{array}{l}\text { extraction } \\
\text { of mineral resources }\end{array}$ & $\begin{array}{c}1.299^{*} \\
(0.358)\end{array}$ & $\begin{array}{c}1.963 \\
(6.038)\end{array}$ & $\begin{array}{c}\mathrm{e}^{-21.268} \\
(53.958)\end{array}$ & 0.718 & $8.89^{*}$ & $Y=e^{-21.268} \cdot K_{t}^{1.299} \cdot L_{t}^{1.963}$ \\
\hline processing plants & $\begin{array}{c}0.110 \\
(0.335)\end{array}$ & $\begin{array}{c}-0.934 \\
(4.602)\end{array}$ & $\begin{array}{c}\mathrm{e}^{19.196} \\
(9.02)\end{array}$ & 0.521 & 3.81 & $Y=e^{19.196 \cdot} \cdot K_{t}^{0.11} \cdot L_{t}^{-0.934}$ \\
\hline $\begin{array}{l}\text { production and } \\
\text { distribution of electric } \\
\text { power, gas and water }\end{array}$ & $\begin{array}{c}0.589^{*} \\
(0.117)\end{array}$ & $\begin{array}{c}-4.119 * \\
(0.907)\end{array}$ & $\begin{array}{c}\mathrm{e}^{42.372} \\
(9.369)\end{array}$ & 0.936 & $51.553^{*}$ & $Y=e^{42.372} \cdot K_{t}^{0.589} \cdot L_{t}^{-4.119}$ \\
\hline
\end{tabular}

Table 3. Total average aggregate performance indicators for the regional industries

\begin{tabular}{|l|c|c|c|c|c|}
\hline Industry branch & $\boldsymbol{\alpha}$ & $\boldsymbol{\beta}$ & $\boldsymbol{\alpha}+\boldsymbol{\beta}$ & $\begin{array}{c}\text { Change in } \\
\text { production } \\
\text { performance }\end{array}$ & Production technology \\
\hline $\begin{array}{l}\text { Entire industry } \\
\text { including }\end{array}$ & 0.474 & -1.469 & $\alpha+\beta<1$ & decrease & labour-intensive \\
\hline extraction of mineral resources & 1.299 & 1.963 & $\alpha+\beta>1$ & increase & capital-intensive \\
\hline processing plants & 0.110 & -0.934 & $\alpha+\beta<1$ & decrease & capital-intensive \\
\hline $\begin{array}{l}\text { production and distribution of } \\
\text { electric power, gas and water }\end{array}$ & 0.589 & -4.119 & $\alpha+\beta<1$ & decrease & \\
\hline
\end{tabular}

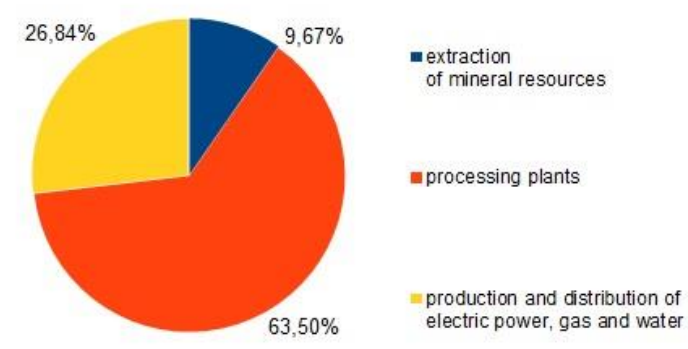

Figure 5 Structure of the employment in the industry branches of the Astrakhan Region in 2009 (\%)

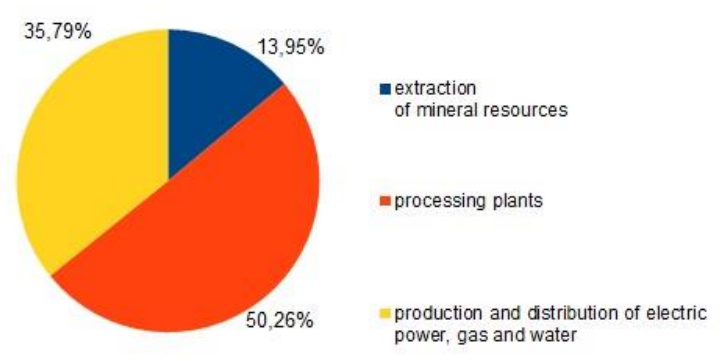

Figure 6 Structure of the employment in the industry branches of the Astrakhan Region in 2018 (\%)
The parameters $\alpha$ and $\beta$ show the value of the average annual growth of the final product per $1 \%$ of the growth of the corresponding production factor, assuming the invariability of the other factor. As it is seen, the initial pre-condition accepted by Cobb and Douglas as $\alpha+\beta=1$ is not valid for any industry. The total average aggregate performance indicators for the regional industries are presented in Table 3.

Generally, $\alpha+\beta<1$ for the industry which shows the decrease in the average aggregate performance indicator for the period under review. Economically, we can talk in this case about the negative effect of expanding the production scale. The output increases more slowly in comparison to the growth of costs of production factors; their total efficiency decreases.

The negative effect of the production expansion takes place in the industries of the Astrakhan Region dealing with the production and distribution of electricity, gas and water and processing plants. In such an industry branch as extraction of mineral resources, the obtained parameters of production function are $\alpha+\beta>1$, and this means that the average aggregate indicator of efficiency in the specified industries was rising, i.e. there was the positive effect of expansion of production scale.

For the industry as a whole, as well as for the processing plants and production and distribution of electric power, gas and water, the labour elasticity is negative which means the inverse relationship between the dynamics of production output and the dynamics of the number of labour resources. As the labour resources employed in the 
industry are decreasing, the production output in overall has grown over the past 10 years.

The dynamics of production volumes in the industry of the Astrakhan Region have been mostly influenced by the reduction of labour resources and less significantly by the increase in the price of fixed assets. The high elasticity of production output in the labour of all the branches indicates this (The indicator $\beta$ in Table 3 to the modulo is much higher than indicator $\alpha$ ). As the indicator $\beta$ is negative and $\alpha$ is positive, it is possible to draw conclusion that the industry of the Astrakhan Region is characterised by using the capital-intensive technology. As Table 3 shows, $\alpha>\beta$ for every industry branch except for the extraction of mineral resources. This means that each per cent of growth rate in capital gains, relative to labour, provides a greater increase in output growth. This fact can be considered as an indirect evidence of more efficient use of capital in the industry of the Astrakhan Region. The technology in the industry of extraction of mineral resources is characterised, on the contrary, as labourintensive.

The calculation of the parameters of production functions demonstrates that the production performance in the Astrakhan Region is not high; there is a de-intensification of production and economic growth.

One of the important trends in the implementation of production functions is to use them for analyzing the factors or causes of economic growth. Such analysis is aimed at identifying the quantitative and qualitative components of economic growth. As it has already been discussed, the use of production functions makes it possible to solve the fundamental task of assessing the separate influence on the economic growth of different groups of factors.

It is traditional to divide the factors of economic growth into extensive and intensive ones. This classification is grounded on the nature of economic growth process. Under the influence of extensive factors, the economic growth is achieved due to a change in the quantitative characteristics of the production factors introduced into the economic system by maintaining qualitative characteristics at the same level. The extensive growth sources include:

(1) increase in the volume of introduced production assets maintaining the current level of technology, i.e., increasing the capital-labor ratio; (2) increase in the number of employees in the production with their constant professional qualification characteristics; (3) increase in the volume of consumed material resources without changing their quality.

Consequently, the extensive factors can be defined as an increase in the saturation degree of the production system with the production means. The production can be driven up in an extensive way when unused production factors are available.

With regard to the intensive growth factors, it can be mentioned that they are characterized as factors of higher order than extensive ones, since the influence of intensive factors on the economic growth implies the improvement of the quality of production factors. The effect of these factors is to reduce the costs per unit of output. The main components of this group of factors are: (1) improvement of the characteristics (both technical and technological) of existing and introduced fixed assets; (2) advances in the structure of fixed assets: increase of active part of fixed assets, share of specialized and automated equipment, optimization of age structure of fixed assets; (3) growth in capital productivity of fixed assets; (4) growth of application rate fixed and current assets; (5) upgrade of the level of qualification, professional training and refresher training and the accumulation of experience by employees; (6) improvement of labor productivity due to the development of the results of scientific and technical progress, organization and working environment; (7) expanding of human capital, i.e. development of educational potential of employees; (8) rationalization of redistribution of production means and enlargement of its scale which causes the effect of positive returns to scale; (9) introduction of finished cycles into the production, concentration and specialization of production.

So, it is possible to distinguish 3 subgroups in the group of intensive factors: (1) increase of the efficiency in using fixed and current capital; (2) improvement of labor efficiency; (3) emergence of returns to scale.

The concepts of "intensification of production" and "economic efficiency", which are often identified by many researchers, need to be distinguished, as noted by A.I.Anchishkin in the 1970s [7]. The differences lie in the economic sense of these criteria. The economic efficiency describes with its indicators the ratio of output (average or limiting output ratio) to the production factors that provide this output. However, this relation can vary over time, which enables to track the progress of performance indicators. In contrast, the intensification of production through its criteria shows the ratio of the increase in production due to the change in the economic efficiency of production factors to the increase in production volumes provided by the quantitative increase in the introduced factors of production. The production intensification can also be described by the comparison of the growth of production volumes due to the change of the efficiency of production factors to the total growth of production volumes.

Thus, these concepts are distinguished in the view of the state of dynamics and statics. The production efficiency can be calculated both in a static and in a dynamic condition, but the level of production intensification is only a dynamic concept. As a result, the production intensification characterizes, among other parameters, the process of dynamic changes in production efficiency and allows us to determine the relative contribution to the increase in production of efficiency changes.

At the same time, the improvement of production efficiency, when the extensive sources of economic growth expand rapidly, does not mean its intensification, but the intensification of production is possible, even if the growth rate of production efficiency drops. This can happen in the situations when the extensive sources of growth decrease or their expansion rate is lower than the growth rate of economic efficiency. 
The analysis of the industry development based on the production function made it possible to single out another group of factors, the so-called unidentified growth factors. Klass A. and Chetyrkin E.M. describe this combination of factors as "disembodied technological progress" [8]. In authors' opinion, this interpretation is too narrow because this group of factors includes only technical and technological innovations that are not taken into account in the price of fixed assets or in the characterisation of production employees, but involves much more diverse processes.

It is proposed to define this group of factors as "market factors of economic growth". Under market factors it is advisable to understand such factors when the economic growth is achieved due to a change in the general conditions for the implementation of the reproduction process. These factors should include: (1) improvement of management processes and organizational and technical forms of production; (2) structural and sectoral shifts in the economy; (3) fluctuations of economic conditions: business activity, legal framework for business activity, consumers' purchasing power and demand, parameters of production market factors; (4) changes in the sociodemographic situation (birth rate dynamics, changes in the age structure of the population, etc.); (5) qualitative changes, such as technical innovations which are not reflected in the characteristics of the fixed assets and labour involved in the production process; (6) the level of rationality in the expenditures for research and development activities, as well as the relation between theoretical developments and their practical use; (7) change of conditions and peculiarities of forming the used production factors; (8) change of priorities and directions of national and regional policy.

So, the intensive factors represent the qualitative changes that can be quantified for a specific size and composition of the used production factors. Unlike intensive factors, the market factors of economic growth are those ones which can be measured only by the degree of their combined influence, but it is impossible to determine the contribution of the single components of that total market characteristics that determined the conditions of reproduction in a given period.

The further in-depth analysis of the industry of the Astrakhan Region reveals its major problem areas: (1) significant wear and tear of fixed assets; (2) insufficient application of existing and additional production facilities in a number of industries of the Astrakhan Region; (3) limited demand for products of local producers; (4) achieving the production concentration limits in some cases; (5) inefficient management, etc..

According to the estimates of the reliable Russian magazine "Expert" which annually studies the investment climate in the Russian regions, the Astrakhan Region (for the end of 2017) is a 3B1 group region with a reduced investment potential and moderate investment risk [9]. At the same time, the region moved from the 61st to 63rd place in terms of risk level for 2016-2017 and from the 58th to 60th place among all regions of the Russian Federation in terms of its potential level.
Evaluating the components of investment risk and potential, the credit rating agency "Expert RA" uses about 200 initial quantitative and qualitative characteristics. From the investors' point of view, the most significant is the infrastructure, production, labour and consumer potential. At the same time, the investors consider the legislative, financial and political risks the most significant. The lack of infrastructure is one of the main problems that reduce the investment appeal of the region for investors. In accordance with the methods of the credit rating agency "Expert RA", the Astrakhan Region took the 56th place among all the subjects of the Russian Federation in terms of infrastructure potential [9].

\section{CONCLUSION}

The determination of the role of factors using the production function and, consequently, the sources of growth, enables the use of this analysis and forecasting tool to set the general future problems of economic growth. Naturally, the calculation of "factor contributions" is not absolute and only possible as the application of production function tools for these purposes is based on the acceptance of certain conditions.

Taking into account the results of the analysis, it is possible to conclude that nowadays there is a need to increase fixed assets of the industry, especially since their depreciation is quite high, and to optimise the number of staff in most industries. The influence of fixed assets on the change in the production output is not greatly significant in most cases, which, in the authors' opinion, is associated with a low degree of implementation of existing and additionally introduced production capacities in most industries of the Astrakhan Region. The low degree of the implementation of production capacities is caused by the following reasons: limited demand for products of local manufacturers, high deterioration of fixed assets, and achievement of production concentration limits. These and other reasons (for example, inefficient management) lead to the de-intensification of production, i.e. the increase in the introduced resources results in the decrease in the production effectiveness. The inflow of investment into the industry is reasonable, and this is linked with the need to form a new industrial base for the industrial production in the long term.

Consequently, the solution of the problems, that the economy of the Astrakhan Region faces, first of all, should be associated with the increase of the introduction of intensive factors for the economic growth, i.e. the intensification of production.

\section{REFERENCES}

[1] E.P. Karlina, I.L. Chirkova, Specific features of the formation of industrial policy at the meso-level (in terms of Astrakhan Region), Scientific and Technical 
[5] Business activity. Federal State Statistic Service. Retrieved from https://astrastat.gks.ru/folder/43611. Access on 15.11.2019.

[6] Labour market and employment. Federal State Statistic Service. Retrieved from https://astrastat.gks.ru/folder/41533. Access on 15.11.2019.

[7] A.I. Anchishkin, Forecasting the Growth of the Socialist Economy. Moscow: Economics, 1973.

[8] Chetyrkin E.M., Klass A., (Ed.) Theory and Practice of Statistical Modelling of Economy, Moscow: Finances and Statistics, 1986.

[9] The investment climate of the regions - 2017. Expert. December, 2017. Retrieved from https://raexpert.ru/ratings/regions/2017. Access on 21.11.2019. 